\title{
Spinal Cord Injuries in Enugu, Nigeria-Preventable Accidents
}

\author{
C. A. Okonkwo, MB BS (Ibadan), FRCS (Glas), FICS, \\ FWACS \\ Accident and Orthopaedic Unit, Department of Surgery, University of Nigeria \\ Teaching Hospital, PMB 01129, Enugu, Nigeria, W. Africa
}

\section{Summary}

This is a review of 72 patients who were treated for Spinal Cord Injuries in the University of Nigeria Teaching Hospital, Enugu, Nigeria, during the period Fanuary 1980 to Fanuary 1985. There were 20 patients who had tetraplegia as a result of their injuries and 52 with paraplegia. All the patients were treated conservatively.

The catchment area of the hospital is in the rain forest belt of West Africa where tall palm trees grow. Palm tree climbers use jigs which are woven from palm fronds. The climbing jigs are prone to snapping during periods of low humidity between the months of November and March. During this period of the year the tensile strength of the jigs is greatly reduced.

Our experience is that the commonest cause of spinal cord injury is a fall from palm trees. Climbers should be educated about the time related jig failure, falls and subsequent spinal cord injury. Alternative sources for stronger materials for weaving jigs, and increased growing of shorter species of palm trees from which harvesting of palm nuts take place at ground level are advocated.

Other causes of spinal cord injuries and preventive measures are discussed.

Key words: Spinal cord injuries; Preventable accidents; Spinal injuries in Nigeria.

Unlike developed countries, the treatment of spinal cord injuries in developing countries is very much part of orthopaedic, neurosurgical and general surgical services. There is a lack of appreciation by health planners in developing countries of the special need for the total care of spinal injuries patients. There is also a lack of manpower and there are financial constraints. In the light of these difficulties, preventive measures should be adopted by developing countries to achieve reduction in accidents including spinal cord injuries. Burke (1973) showed that the adoption of road safety measures, constant use of seat belts and reduction of speed limits produced a $27 \%$ decline in the rate of injuries. 
Watson (1983) also showed that only $3 \%$ of seat belt wearers sustained severe neck injuries in road accidents where $97 \%$ sustained only minor injuries.

Bedbrook (1979) concluded that education, improved rules for road users and water sports, protective orthoses, and eradication of psychogenic factors would help to lower the incidence even further. This paper reviews 72 patients with spinal cord injuries who were treated in the University of Nigeria Teaching Hospital, Enugu, Nigeria, during the period January 1980 to January 1985. The objective is to highlight the causes of spinal injury and the changes required to reduce the occurrence of spinal injuries. Prevention is an important factor in reducing the incidence of falls from palm trees and other injuries and therefore of spinal cord injuries in the rain forest belt of Nigeria.

\section{Patients and methods}

Casualty case records of patients with the diagnosis of spinal cord injury were reviewed. Patients referred from centres in the catchment area of the hospital to surgical and other outpatient clinics with a diagnosis of spinal cord injury were included in the study. There was a total of 90 patients over the 5 year period with a diagnosis of a spinal cord injury 79 of these patients passed through the hospital casualty department, while 11 others were referred from other centres to surgical and other outpatient clinics in the hospital. Eighteen cases were not included in the study because 12 case records did not state the cause of the injury, and 6 other case records were missing.

\section{Analysis of results}

A breakdown of the figures shows that there were 4 females who were all paraplegic and 68 males (Table I). Forty-eight males were paraplegic and all 20 tetraplegics in the study were males. Three of the four females in the study were involved in road traffic accidents while the fourth female had had a fall at home.

Table I Age group and sex of patients

\begin{tabular}{cccc}
\hline & & \multicolumn{2}{c}{ Sex } \\
\cline { 3 - 4 } Age group & No & Male & Female \\
\hline $10-19$ & 10 & 10 & - \\
$20-29$ & 14 & 14 & - \\
$30-39$ & 18 & 16 & 2 \\
$40-49$ & 22 & 20 & 2 \\
$50-59$ & 6 & 6 & - \\
$60-69$ & 2 & 2 & - \\
Total & 72 & 68 & 4 \\
\hline
\end{tabular}

\section{Falls from palm trees}

Twenty-nine males fell from palm trees whilst either tapping palm wine, or harvesting palm fronds and palm nuts. The 40-49 age group were at the greatest risk, followed by those in the 30-39 age group (Table II). There were no falls 
Table II Falls from palm trees

\begin{tabular}{cc}
\hline Age group & No. of patients \\
\hline $20-29$ & 4 \\
$30-39$ & 8 \\
$40-49$ & 12 \\
$50-59$ & 6 \\
$60-69$ & 2 \\
Total & 32 \\
\hline
\end{tabular}

from palm trees in the 10-19 age group, but 50-59 and 60-69 age groups had 6 and 2 falls respectively.

Other types of falls

Five patients in the study were involved in other types of falls. Four were in the 10-19 age group and the fifth patient was the woman who fell at home, referred to previously.

\section{Diving injuries}

All 6 patients in this group were males. Four were in the 10-19 age group, and 2 in the 20-29 age group. They were diving into shallow village streams.

\section{Matchet/knife injuries}

Four patients had matchet or knife stab wounds as the cause of spinal cord trauma. Three were butchers and were stabbed with carving knives, the fourth patient was matcheted over the mid-thoracic spine in a row on a community farmland.

\section{Gunshot wounds}

Two patients were shot in separate armed robbery incidents.

Road traffic accidents

This was the cause of spinal cord injuries in 26 of the 72 patients under review.

\section{Discussion}

Falls from palm trees, as shown in this study (Table III), accounts for more spinal cord injuries than road traffic accidents in parts of the eastern rain forest belt of Southern Nigeria. All falls in this study accounted for nearly $50 \%$, and compares with the findings of Shanmugasundaran (1978-1984) in the Madras Study, which showed that all falls accounted for $66 \%$ of all spinal cord injuries. In Madras there were falls into wells, which contributed to the increased number of falls. This is an uncommon injury in Southern Nigeria where natural springs and rainfall have been the traditional sources of water supply.

Another series, Iwegbu (1983) from Zaria in Northern Nigeria showed that road traffic accidents accounted for $75 \%$ of spinal cord injuries. Northern 
Table III Cause of injury

\begin{tabular}{lcr}
\hline \multicolumn{1}{c}{ Cause } & No. of patients & $\%$ \\
\hline Fall from palm tree & 29 & 41 \\
Road traffic accident & 26 & 36 \\
Diving accidents & 6 & 8 \\
Falls (not from palm tree) & 5 & 7 \\
Matchet and knife injury & 4 & 5 \\
Gun shot wounds & 2 & 3 \\
Total & 72 & 100 \\
\hline
\end{tabular}

Nigeria is in the Sub-Sahara zone with very little rainfall. The level of rainfall is inadequate to support the growth of palm trees in this part of Nigeria. Falls from trees (not palm trees) in the Zaria study accounted for $8 \%$ of all spinal cord injuries.

Palm trees belong to the tree family Palmae. Their stems are as tall as 3 meters, upright and unbranched. They have large pinnate leaves similar to coconut leaves, but unlike coconut, palm leaves are wider in shape and palm nuts grow in clusters in a bunch. There are between 500 to 2,000 palm nuts in a bunch with spiky thorns sandwiching the nuts. A mature, ripe bunch of palm nuts weighs as much as $10 \mathrm{~kg}$ weight. This thorny structure as well as the weight make it an arduous task for farmers to prevent spinal injuries in man by training monkeys to harvest the palm nuts as Sir L. Guttmann (1979) had humorously suggested following a Malaysian experience during the war when a farmer trained his monkey to pluck coconuts. Harvesting will in the future be more carefully and efficiently done by man. The method of harvesting should be reviewed in the light of the consequences of falls from palm trees. Palm nuts ripen during the months between November and March, which are the dry periods of the year in Southern Nigeria, when latent cracks have been observed in climbing jigs (unpublished data). These jigs are as thick as $6-8 \mathrm{cms}$, and are $315 \mathrm{cms}$ long on the average. They are firmly hand woven with materials from palm fronds by experienced traditional weavers. Considerable confidence placed on these weavers does not seem to give much room for more regular and thorough inspection of these jigs before climbers subject them to pressures of the regular climbing of palm trees. It is advocated that more regular and careful inspection of jigs be made or, alternatively, freshly woven jigs of good tensile strength be reserved for use during the period when the weather is hazardous for climbing palm trees. Furthermore, other species of the tree family Palmae, namely Raffia and Rattan (cane) which are extensively used traditionally for other domestic ropes, should be woven and used as palm tree climbing jigs. Though not used traditionally for this purpose, these can withstand the adverse low humidity of the dry season well. Horticulturists working in research centres in Nigeria have recently developed palm tree species which do not grow more than $60-90 \mathrm{cms}$ tall and fruit abundantly. Harvests are made by farmers standing at ground level, and therefore there is no need whatsoever to climb. This species was developed because of its potential for a higher yield, without the medical implications in mind.

For man and medicine, this new discovery, a shorter species, which eliminates the necessity for climbing ought to be fully exploited and this species made 
available to all farmers. The two facts, alternative more durable materials for jigs, and the widespread growing of new shorter species are important weapons for community education. Expectation is high that these will influence the prospects of reducing spinal injury in this area in future.

\section{Diving}

Of the spinal cord injuries in this study $8 \%$ resulted from diving into shallow village streams. These streams provide swimming recreation for village communities who do not have standard swimming pools. The depths of these streams are unexplored and warning notices ought to be displayed restricting diving into streams of acceptable depths, and in standard swimming pools where they exist. Community education involving schools and teachers should be encouraged to reduce injuries due to ill advised diving. The dangers of diving into shallow water as emphasised by Frankel (1979) should be effectively taught when young people are learning to swim.

\section{Other falls}

Seven per cent of injuries to the spinal cord were due to falls other than falls from palm trees. One of the four women in the study fell at home. After her injury, she was treated by a traditional bone setter. Traditional bone setters use traction and massaging as their main method of treatment of musculo-skeletal injuries. They do not have access to any radiological investigations. They are the trauma and orthopaedic equivalents of the WHO trained and recognised Traditional Birth Attendants. The woman was reported to have been moving all her four limbs before she was treated by the traditional bone setter. She became paraplegic after this treatment and attended the orthopaedic outpatient clinic four months after her injury. She had sustained an L1 vertebral fracture with a flacid paraplegia.

From the above, it is obvious that there is a need to follow the example of modern obstetricians and seek WHO sponsored identification and training of traditional bone setters in musculo-skeletal injuries in a programme similar to that of traditional birth attendant trainees. Since the training began in the 1960s, traditional obstetric practice in East and West Africa have shown reduction in malpractices, morbidity as well as mortality from neonatal tetanus. The fate of this woman described in this study is certainly one of many similar patients and is preventable with proper community education.

The remaining four patients in this group are in the 10-19 age bracket. Three of them fell while climbing mango trees. Mango trees grow wild in the woods, to characteristic heights and have multiple branches. Falls from this tree are commonest during the months of April, May and June, when their fruits ripen for harvest.

Only recently with export in mind, short, high yielding varieties are being developed by research stations in the area. This variety remains dwarfed while its yearly fruits are plucked by farmers standing at ground level. Like the palm tree, short species development was without the implication of the prevention of falls and associated injuries in mind. There is enormous potential to abolish 
falls from climbing when this short mango species is grown not only in family orchards but also by large and small scale farmers.

\section{Road traffic accidents}

Though second to falls as a cause of spinal injury, the causes of road accidents as in other parts of Nigeria include the types of and the condition of motor vehicles, the condition of road surfaces, road markings and warning signs, the attitude of drivers and pedestrians as well as lack of legislation for the compulsory wearing of seat belts, etc.

The Peugeot family estate and saloon cars are most commonly used for long distance intercity taxi services in many parts of Nigeria. This brand of vehicle is noted for its accelerating ability. Excessive speeds, especially in hot weather, expose vehicle tyres to very high temperatures resulting in a high incidence of burst tyres. Many country roads, are asphalted (built since 1970s and are therefore favourable for fast driving, with the possibility of many road accidents.

Another important factor is the use of seat belts. Though cars are fitted with seatbelts (usually for front seats only) these are rarely fastened by drivers and front seat passengers. Where skidding occurs, occupants of cars-family and saloon models-are thrown about in the car several times and occasionally out of the car while skidding is in progress. Spinal injuries are therefore not uncommon amongst other injuries in such accidents.

Intercity coaches-a mass transit means of transport-usually have low chassis. Accidents involving this form of transport occur when the coaches are driven through road bends at great speed. The number of people injured is large when it is remembered that many coaches accommodate 45 or more people.

Road markings, traffic sign posts or road repair and obstruction signs are often poorly visible. The road markings may have been washed out by heavy rains which are common, and these markings are rarely repainted, or the displaced signs replaced after they have been knocked over by vehicular traffic. These are some of the factors contributing to an accident rate often referred to as one of the highest in the world. These practices can be prevented by proper community education. Accidents will be greatly reduced where road signs are well positioned and regularly renovated or replaced if displaced. The wearing of seat belts should be encouraged and law enforcement agencies ought to remind road users about safety measures backed by law.

\section{Conclusion}

There is a wide range of areas where community education has helped developed societies to reduce accidents, these should be as effective if applied to Nigeria. The limitations of developing modern spinal injury units at present must give way 'to prevention applied to primary eradication of spinal paralysis as a major goal' Bedbrook (1984). The challenges of the future in the care of spinal injury in developing countries as well as developed nations depends on prevention and future basic research on preventive measures in the years ahead. 


\section{References}

BEDBROOK G 1979 Spinal Injuries with Tetraplegia and Paraplegia. The Fournal of Bone and foint Surgery Vol 61-B, No 3 267-284.

BEDBROoK G 1984. 1984 Lee Lecture. Spinal Man: Past, Present, Future. Fournal of Western Pacific Orthopaedic Association. Vol XXII No 1, 1-10.

BURKE D C 1973 Spinal Cord Injury and Seat Belts. Medical fournal of Australia 2:801-806.

Frankel H L 1980 Spinal Cord Injuries due to diving. Paraplegia 18:118-122.

SIR L Guttmann 1979 General discussion of Papers. Paraplegia 17:428-429.

IwEGBU C G 1983 Traumatic Paraplegia in Zaria, Nigeria: The Case for a Centre for Injuries of the Spine. Paraplegia 21:81-85.

Shannugasundaram T K 1978-1984 PL 480. Paraplegic Project Madras-The Mode of Injury in PL 480, page 21.

Watson N 1983 Road Traffic Accidents, Spinal Injuries and Seat Belts. Paraplegia 21:63-64. 